\title{
SOLUÇÃO PARA A CRISE CARCERÁRIA TEM SIGNIFICATIVO REFLEXO ORÇAMENTÁRIO
}

\begin{abstract}
Coluna publicada em 25.8.2015: <http://www.conjur.com.br/2015-ago-25/contasvista-solucao-situacao-carceraria-significativos-reflexos-orcamentarios $>$
\end{abstract}

A situação carcerária no Brasil é um problema antigo, grave e recorrente. A questão voltou ao debate no mundo jurídico com a decisão de 13 de agosto de 2015 em que o Supremo Tribunal Federal, no Recurso Extraordinário 592.581, nos termos do voto do relator, ministro Ricardo Lewandowski, determinou ao Poder Executivo a realização de obras em estabelecimento prisional, dadas as condições extremamente precárias em que se encontrava. ${ }^{1}$ Uma decisão interferindo diretamente em política pública que envolve montantes expressivos de recursos públicos, tendo, portanto, significativos reflexos orçamentários.

As políticas públicas voltadas à administração penitenciária estão entre as que mais dependem de recursos públicos para serem bem-sucedidas, fazendo dos instrumentos financeiros à disposição do Estado as "armas" no combate aos permanentes problemas que afligem o setor, o que traz os orçamentos públicos para o centro do debate.

E estão entre as mais complexas no âmbito da administração pública, por envolver os entes da Federação e a participação de todos os poderes, o que, evidentemente, exige uma nem sempre fácil "engenharia" para viabilizar a cooperação entre entes, órgãos e instituições dotados de autonomia, tornando necessária uma integração intersetorial, interinstitucional e federativa na sua concepção, organiza-

1 Por unanimidade, a Corte Suprema cassou o acórdão do Tribunal de origem (TJ-RS), que havia decidido não competir ao Poder Judiciário determinar ao Poder Executivo a realização de obras em estabelecimento prisional, por configurar invasão indevida em seu campo decisório, e manteve a decisão do juízo de primeiro grau, reconhecendo a procedência do pedido formulado pelo Ministério Público. 
ção, implementação, gestão e execução, esperando-se dos entes federados "um indispensável senso de cooperação", como bem colocado pelo ministro Gilmar Mendes. ${ }^{2} \mathrm{O}$ próprio governo federal reconhece que "a situação carcerária é uma das questôes mais complexas da realidade social brasileira (...). O equacionamento de seus problemas exige, necessariamente, o envolvimento dos três Poderes da República, em todos os níveis da Federação, além de se relacionar diretamente com o que a sociedade espera do Estado como ator de pacificação social". ${ }^{3}$

A administração do sistema prisional coloca à prova a capacidade de o Estado fazer valer a Constituição, uma vez que nela está expresso, entre os direitos e garantias fundamentais, que "é assegurado aos presos o respeito à integridade física e moral" (CF, art. 5, XLIX), além de impedir penas cruéis (art. 5, XLVII) e estabelecer que a pena seja cumprida em estabelecimentos distintos, de acordo com a natureza do delito, idade e sexo do apenado (art. $5^{\circ}$, XLVIII), entre outros. E não é o que se tem observado, diante das muitas constatações de situações degradantes, como o próprio acórdão citado menciona. Estando o encarcerado sob a custódia do Estado, este se torna integralmente responsável por fazer valer os respectivos direitos fundamentais previstos na Constituição. $\mathrm{O}$ que não é fácil e exige do Poder Público que, sem prejuízo das inúmeras e legítimas demandas de toda a sociedade, em áreas prioritárias como saúde, educação, segurança pública e outras que também importam em elevado aporte de recursos, não possa descuidar dessa que é uma determinação constitucional voltada a assegurar direitos fundamentais para pessoas que estão sob sua exclusiva guarda e responsabilidade, colocando nos ombros dos governantes o ônus de fazer as chamadas "escolhas trágicas".

A adequada alocação dos recursos públicos, associada à gestão eficiente, de forma cooperativa entre os entes federados e os poderes, torna-se fundamental para que se possa dar uma solução para a situação carcerária. Convém não esquecer que resolver esse problema não é somente essencial para manter a dignidade daqueles que estão presos, mas também uma forma de permitir que a pena seja efetivamente um instrumento de ressocialização e consequente pacificação social, em benefício de toda a sociedade.

No âmbito financeiro, as políticas públicas voltadas à situação carcerária abrangem a participação de todos os entes da Federação, especialmente a União e

Segurança Pública e Justiça Criminal, publicada no ConJur, 4 de abril de 2015.

3 BRASIL. Ministério da Justiça. Depen - Departamento Penitenciário Nacional. Levantamento nacional de informaçôes penitenciárias - Infopen. Brasília: Ministério da Justiça - Depen, junho de 2014, p. 6. 
os Estados, ${ }^{4}$ havendo aporte de recursos dos orçamentos de todos os entes federados envolvidos. Releva destacar também a intersetorialidade das políticas públicas do setor, que incluem questôes de saúde pública, educação, segurança e outras, exigindo também uma coordenação de várias áreas da administração pública.

Destaca-se como principal instrumento financeiro o Funpen (Fundo Penitenciário Nacional), criado pela Lei Complementar 79, de 7 de janeiro de 1994, ${ }^{5}$ fundo de natureza contábil que integra o orçamento fiscal da União e principal fonte de recursos para as açóes governamentais de grande parte dos entes federados, por meio de transferências voluntárias, via convênios e, no caso de obras pública, por contratos de repasse. ${ }^{6}$ Faz dos fundos e transferências intergovernamentais voluntárias os instrumentos por excelência que permitem operacionalizar o financiamento desta política pública de forma mais eficiente em nosso federalismo cooperativo.

Chama a atenção saber que boa parte do orçamento deste fundo não é executada. Ante a atual situação de precariedade do nosso sistema prisional, não há como se admitir que, havendo recursos disponíveis, não sejam utilizados, o que se constata pelo frequente contingenciamento das dotaçôes orçamentárias do Funpen, que já vem de longa data. ${ }^{7}$ Póe por terra eventuais argumentações pela aplicação da teoria da reserva do possível como justificativa para o não atendimento das necessidades do setor, não somente em razão da evidente prioridade ante as situações de flagrante violação do princípio da dignidade humana, como também pela impossibilidade de se alegar falta de recursos que estão contemplados no orçamento público.

Além da melhor adequação na captação e distribuição dos recursos, nunca se pode esquecer o aperfeiçoamento na gestão pública, repleta de falhas nesse setor, por deficiência no planejamento, ausência de boa governança, ações improvisadas, desinteresse político, falta de capacitação específica de gestores, somando-se fatores que levam a uma situação caótica, como reconheceram recentemente vários especialistas no tema. ${ }^{8}$ Pouco vale destinar mais recursos se forem mal utilizados,

4 Compreendendo-se sempre, ao mencionar os Estados, também o Distrito Federal.

5 E regulamentado pelo Decreto 1.093, de 23 de março de 1994.

6 Ainda que não represente, em termos quantitativos, os valores mais expressivos, tendo em vista que não incluem as despesas com pessoal, como destaquei em Financiamento da segurança pública precisa de atenção, nesta edição, p. 65-68.

7 Apesar do déficit de 200 mil vagas, Fundo Penitenciário tem R \$ 1 bi em caixa - dinheiro não é o problema principal em crise do sistema penitenciário, por Jailton de Carvalho, O Globo, 16 de janeiro de 2014; Fundo penitenciário é alvo de contingenciamentos do governo. Folha de S.Paulo, 20 de fevereiro de 2001.

8 Sistema penitenciário é exemplo de gestão ineficiente no País. O Estado de S.Paulo, 17 de março de 2015. 
tornando a gestão mais eficiente uma necessidade tão premente quanto o maior aporte de dinheiro.

Há necessidade de se dar especial atenção ao problema, que é potencialmente muito grave, dado o crônico déficit de vagas no sistema carcerário, ${ }^{10}$ que pode se agravar muito, se não forem implementadas ações estruturais de grande porte e alto custo. Ainda que se tenham tomado medidas recentes de grande relevância em termos de Justiça, e colaborado para reduzir o encarceramento indevido, como os mutirōes carcerários e as recém-implantadas audiências de custódia, ${ }^{11}$ responsáveis, respectivamente, por não deixar pessoas presas indevidamente, liberando-as quando cabível e evitando que fossem encarceradas desnecessariamente, o problema persiste; principalmente por se constatar haver dezenas de milhares de mandados de prisão não cumpridos $^{12}$ e uma maior eficiência da administração pública na captura de fugitivos levaria a um colapso do sistema, que já conta com mais de 600 mil presos, segundo levantamento recente..$^{13}$

A persistência dessa situação insustentável sob todos os pontos de vista - humano, social, jurídico etc. - levou mais uma vez o Poder Judiciário a ser chamado para interferir na gestão pública, compelindo o Poder Executivo a promover as ações governamentais necessárias para assegurar os direitos fundamentais violados. E respondeu asseverando, em repercussão geral, que "é lícito ao Judiciário impor à

9 Questão para a qual já chamei a atenção em Não falta dinheiro à administração pública, falta gestão, nesta edição, p. 255-258.

10 A crise do sistema prisional. O Estado de S.Paulo, em 9 de junho de 2015. Atualmente o déficit de vagas é de 194.650, segundo o Ministério da Justiça (<http://portal.mj.gov.br/data/Pages/ MJD574E9CEITEMID364AC56ADE924046B46C6B9CC447B586PTBRNN.htm>).

11 Entre outras medidas, como a realização de campanhas em favor da ressocialização, estabelecimento de parcerias com a sociedade civil para apoiar as ações de reinserção, criação de banco de oportunidades de trabalho, educação e capacitação profissional e o acompanhamento dos indicadores e metas de reinserção e a efetiva participação do Conselho Nacional de Justiça nessa área, como bem destacado pelo ministro Gilmar Mendes (MENDES, Gilmar. Segurança pública e a responsabilidade do Judiciário, Consultor Jurídico, publicado e disponível desde 5 de abril de 2014). E também a realização de audiências por videoconferência, a imposição de penas alternativas, possibilidade de parcerias público-privadas na construção de presídios, todas sendo medidas que podem colaborar para se observar a economicidade na gestão pública neste setor, como já mencionei em Financiamento da segurança pública precisa de atenção, nesta edição, p. 65-68.

12 Segundo informações do Conselho Nacional de Justiça em 2013, havia à época mais de 192 mil mandados de prisão aguardando cumprimento (<http://www.cnj.jus.br/noticias/ cnj/59868-brasil-tem-mais-de-192-mil-mandados-de-prisao-aguardando-cumprimento >).

13 O Brasil conta com uma população prisional de 607.731 pessoas, segundo o Infopen. 
Administração Pública obrigação de fazer, consistente na promoção de medidas ou na execução de obras emergenciais em estabelecimentos prisionais para dar efetividade ao postulado da dignidade da pessoa humana e assegurar aos detentos o respeito à sua integridade física e moral, nos termos do que preceitua o art. $5^{\circ}$, XLIX, da Constituição Federal, não sendo oponível à decisão o argumento da reserva do possível nem o princípio da separação dos poderes” (RE 592.581, rel. Min. Ricardo Lewandowski, j. 13.8.2015).

Mas não é só. Recentemente protocolada, ${ }^{14}$ está em tramitação a Arguição de Descumprimento de Preceito Fundamental 347, movida pelo Partido Socialismo e Liberdade (PSOL). Mais uma oportunidade para que o Poder Judiciário se pronuncie, dessa vez para declarar o "estado de coisas inconstitucional" do sistema penitenciário brasileiro e, ao final, compelir o Poder Público a tomar uma série de medidas, de natureza cautelar e em caráter definitivo, voltadas a equacionar as "gravíssimas violações dos direitos fundamentais dos presos brasileiros, em seu proveito e em prol da segurança de toda a sociedade". Entre elas se destacam, no pedido inicial, as medidas de natureza financeira, como impor "o imediato descontingenciamento das verbas existentes no Fundo Penitenciário Nacional - Funpen, e vede à União Federal a realização de novos contingenciamentos, até que se reconheça a superação do estado de coisas inconstitucional do sistema prisional brasileiro"; determinar ao governo federal que elabore, em três meses, um plano nacional visando a superação dos problemas levantados, no prazo de três anos, plano esse que deve conter a previsão de recursos necessários para a implementação de suas propostas; em seguida, determinar aos Estados que elaborem os respectivos planos, para execução em dois anos, também contemplando a previsão de recursos e cronograma de efetivação das propostas.

Iniciativa ousada e pioneira no Brasil, a medida judicial já foi tomada em outros países, com destaque para a Colômbia, onde a Corte Constitucional já se pronunciou favoravelmente em pedidos análogos, estabelecendo parâmetros e reconhecendo o "estado inconstitucional de coisas" para rejeitar a alegação de insuficiência orçamentária como justificativa para se abster de proteger direitos fundamentais e determinando que sejam tomadas medidas administrativas e financeiras voltadas a tornar efetivos esses direitos fundamentais. ${ }^{15}$

14 PSOL pede intervenção do Supremo no sistema carcerário. Consultor Jurídico, publicado e disponível desde 28 de maio de 2015.

15 Como bem explicitado pelo jurista argentino Horacio Corti (Derechos fundamentales y pressupuesto público: uma renovada relación em el marco del neoconstitucionalismo periférico. In: CONTI, José Mauricio; SCAFF, Fernando F. Orçamentos públicos e direito financeiro. São 
Seria melhor que Constituição estivesse sendo cumprida, sem necessidade de recorrer ao Poder Judiciário para que se façam valer e ver respeitados os direitos e as garantias fundamentais nela previstos. No entanto, ante a inércia estatal, que nesse caso vem de longa data e se mostra evidente, com graves consequências sociais, é um caminho que se mostra plausível e viável e pode colaborar em muito para que se avance em direção à solução desses graves problemas, como já se tem observado nas áreas da saúde e da educação.

Paulo: RT, 2011, especialmente p. 170-174). Veja-se também a petição inicial da citada ADPF 347. 